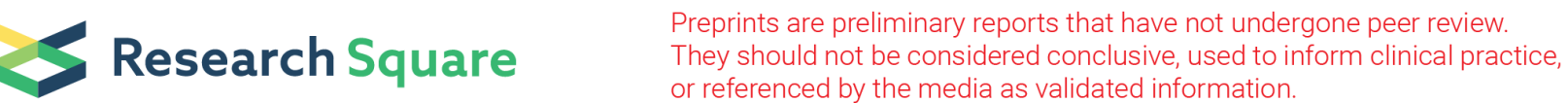

\section{Translation, cross-cultural adaptation, and evaluation of psychometric properties of cystic fibrosis stigma scale}

\section{Victor Hugo Brito Oliveira}

Universidade Federal do Rio Grande do Norte (UFRN)

Karla Morganna Pereira Pinto de Mendonça

Universidade Federal do Rio Grande do Norte (UFRN)

João Carlos Alchieri

Universidade Federal do Rio Grande do Norte (UFRN)

Smita Pakhale

University of Ottawa

Louise Balfour

University of Ottawa

Whitney Houston Barbosa dos Santos Silva

Universidade Federal do Rio Grande do Norte (UFRN)

Ivan Daniel Bezerra Nogueira

Universidade Federal do Rio Grande do Norte (UFRN)

Patrícia Angélica de Miranda Silva Nogueira ( $D$ idpa02@hotmail.com )

Universidade Federal do Rio Grande do Norte (UFRN)

\section{Research Article}

Keywords: social stigma, cystic fibrosis, validation studies

Posted Date: March 3rd, 2022

DOI: https://doi.org/10.21203/rs.3.rs-1193304/v2

License: (1) (1) This work is licensed under a Creative Commons Attribution 4.0 International License. Read Full License 


\section{Abstract}

Background: Stigma is present during the lifespan of individuals with cystic fibrosis (CF); consequently, instruments to assess this psychosocial aspect are necessary. Few instruments are validated and adapted to Brazilian Portuguese. We aimed to translate, cross-culturally adapt, and evaluate psychometric properties of the CF stigma scale.

Methods: We conducted an exploratory study of cross-cultural adaptation involving translation, back translation, revision by an expert committee, and a pre-test. Psychometric properties (content validity, testretest reliability, and convergent validity) were analyzed based on the adapted version of the scale and responded by 52 Brazilian individuals with CF older than 18 years.

Results: Translation and cross-cultural adaptation obtained kappa indexes higher than 0.61 on the expert committee phase and between 0.48 and 0.72 on pre-test. The Brazilian version of CF stigma scale showed excellent psychometric properties: i) internal consistency, $a=0.836$; ii) mean correlation between items and test-retest: $r=0.886, p<0.0001$; and iii) convergent validity, CF stigma scale correlated positively with anxiety scale and negatively with general and specific scores of quality of life in CF.

Conclusion: CF stigma scale was adequately translated and cross-culturally adapted for the Brazilian population. Psychometric properties of the Brazilian version favor its use in future studies regarding stigma conducted with Brazilian individuals with CF.

\section{Introduction}

Technological advances improved treatment accuracy and increased life expectancy (currently estimated at 50 years) of individuals with cystic fibrosis (CF). ${ }^{1}$ However, information about how individuals cope with the disease during adolescence and young adulthood is scarce. ${ }^{2}$ Individuals with CF often present productive cough, repetitive lung infections, and hospitalizations, which may prompt negative perceptions to healthy individuals due to lack of familiarity with disease experiences. ${ }^{3-5}$ In addition, relative premature mortality, physical impact, and low social acceptance of symptoms can be stigmatizing for individuals with $\mathrm{CF}^{5}$

Stigma is defined as any situation in which an individual is not accepted by others, leading to depreciation and distinction on a specific social level. ${ }^{6}$ Health-related stigma occurs when this negative social experience is elicited from a health condition, resulting in social rejection, guilt, or devaluation. ${ }^{7}$ Individuals with CF experience stigma during childhood (e.g., perception of physical differences with siblings due to malnutrition) and in the school environment (e.g., frequent cough and tiredness compared with classmates). At the same time, life routine is altered due to symptoms and the required treatment. These specificities presented in individuals with $\mathrm{CF}$ raise concerns about acceptance, leading to anxiety and fear of social interactions. ${ }^{8}$ 
Distancing from social life may lead to emotional disturbances, such as low self-esteem, generalized anxiety, and feelings of helplessness and depression, and be associated with changes in pulmonary function of individuals with CF. ${ }^{6}, 9$ Social exclusion may cause psychosocial problems, including emotional disorders (e.g., low self-esteem, helplessness, and depression). Stigma may also impair treatment adherence because lack of commitment to the required routine allows individuals with CF to feel more like healthy individuals. In other cases, patients may hide diagnosis, cover up disease symptoms, and conceal pharmacological therapy. ${ }^{6}$

Despite the notable importance of studying stigma in CF, few studies and tools have been formulated to better understand this element. Pakhale et al. ${ }^{10}$ developed and published the CF stigma scale in 2014; an instrument used to assess stigma focusing on CF population. This scale is derived from a scale that evaluates stigma in individuals with AIDS and correlates with questionnaires assessing quality of life, anxiety, depression, and symptom severity. ${ }^{11}$ However, a tool to assess stigma in individuals with $\mathrm{CF}$ is still not available in Brazil. Thus, this study aimed to translate and cross-culturally adapt CF stigma scale to Brazilian Portuguese and evaluate its psychometric properties.

\section{Methods}

We conducted an exploratory study between August 2018 and April 2020 involving translation, crosscultural adaptation, and evaluation of psychometric properties of the Cystic Fibrosis stigma scale. The study was approved by the research ethics committee of the Federal University of Rio Grande do Norte (CAAE: 96606918.3.0000.5537). We adopted ethical principles established in the Declaration of Helsinki and Resolution 466/12 of the National Health Council.

Participants were individuals with CF, parents and/or guardians, and experts (pulmonologists, psychologists, and respiratory physiotherapists). They were informed about objectives, risks, benefits, and procedures of the applied methodology. We also provided information about non-obligation to participate in the study, anonymity of recorded data, and possibility of dropping the study at any phase. Linguistic validation required translators and experts in the field (judges during consensus phase). All participants voluntarily signed the informed consent form before participation and data collection.

\section{Linguistic validation protocol: translation and cross-cultural adaptation}

\section{Qualitative phase}

We requested authorization and cooperation from original authors of CF stigma scale to develop and culturally adapt the scale to Brazilian Portuguese. Dr. Smita Pakhale gave permission, agreed with the study, and assisted in the necessary phases.

Methodological approach was based on steps proposed by Guillemin et al. ${ }^{12}$ and Beaton et al. ${ }^{13}$ and followed recommendations of COSMIN and Mapi Research Institute ${ }^{14}$ : a) translation, b) synthesis of translation, c) back translation and synthesis of back translation, d) review by experts committee using 
Delphi method, and e) pre-test. ${ }^{15-17}$ The two final phases were evaluated using kappa coefficient $(>0.6)$, according to indexes proposed by Landis and Koch. ${ }^{18}$

Adjustments were performed during translation and cross-cultural adaptation to avoid misunderstanding due to literal translation of specific words. Resulting documents were sent to the original author to ensure accordance with the original questionnaire. The expert committee was formed by two pulmonologists, two psychologists, two respiratory physiotherapists, one person whose mother lives with $\mathrm{CF}$, and one individual with CF aged over 18 years; totaling eight participants. Pairs of pulmonologists, psychologists, and respiratory physiotherapists were trained, considering that only one had direct contact with individuals with $\mathrm{CF}$.

Changes in CF Stigma Scale were performed on item 4. The literal translation of the term "bad" to Portuguese is "ruim", and we decided to change to "má" to maintain sense of the sentence. In item 5, the literal translation of the term "disgusting" to Portuguese is "repugnante", which is not widely used in colloquial Portuguese and could modify the original meaning of the phrase. For this reason, we consensually changed to "desagradável". Additional terms underwent slight changes aiming a better understanding by Brazilian individuals with CF. After analysis by the expert committee, kappa coefficient showed values above 0.61 , indicating substantial agreement.

Thirty individuals aged between 18 and 42 years were recruited (22 females) in the pre-test. Educational level ranged from primary education to post-graduation. Clarity and understanding of items evaluated by kappa showed an interval between 0.48 and 0.72 , indicating moderate to substantial agreement. ${ }^{19}$ Last, the Brazilian version of the questionnaire was sent to authors of the original study and experts committee for final approval.

\section{Quantitative phase}

Psychometric properties were evaluated with Brazilian individuals with CF, using the methodological design of the study by Pakhale et al. ${ }^{11}$, after cross-cultural adaptation to Brazilian Portuguese. The scale was applied online. A non-probabilistic sampling of Brazilian individuals with clinical diagnosis of CF (confirmed by sweat test) was used because no specific sample calculation exists for methodological validation studies. Since Landis et al. ${ }^{18}$ recommend five to ten participants for each item to validate a questionnaire, 50 individuals were included (i.e., CF stigma scale has 10 items). Individuals unable to perform or understand procedures and those who underwent lung transplantation were not included.

\section{Recruitment and Questionnaires}

Recruitment occurred via social networks of a Brazilian non-governmental organization (Instituto Unidos pela Vida). Inclusion criteria were presented, and interested individuals were informed to contact researchers for further details. After potential clarifications, a GoogleForms platform ${ }^{\circledR}$ link containing the following information was sent to interested individuals: informed consent form, information on personal data and socioeconomic profile, and four questionnaires (short form of the SF-36v2 Health Survey [SF 
12v2], General Anxiety Disorder [GAD-7], Cystic Fibrosis Quality of Life Questionnaire [CFQ], and translated version of CF Stigma Scale). After a three-week interval, the same questionnaires were reapplied online.

SF12v2 is a self-reported scale that assesses general quality of life. It is a short version of SF-36 scale, adapted to reduce time spent during assessment without impairing quality of evaluation. It consists of 12 items that analyze physical and mental health status of individuals based on previous four weeks. Each item is scored on a five-point scale ranging from "all of the time" to "none of the time" in some cases and from "excellent" to "poor" in others. A cut-off of 50 indicates good quality of life. ${ }^{20}$

GAD-7 is a seven-item self-reported questionnaire used to assess anxiety symptoms based on previous two weeks. Each item addresses a symptom of anxiety and is scored on a four-point scale $(0=$ not at all, 1 = on some days, 2 = most days, and $3=$ nearly every day). Total score ranges from 0 to 21 ; higher scores indicate more severe symptoms of anxiety. GAD-7 was translated and validated for Brazilian Portuguese by Moreno et al., 2016. ${ }^{21}$

CFQ is a self-reported disease-specific questionnaire indicated to individuals aged 14 years or older. It consists of 50 questions covering the following domains: physical, body image, digestive, respiratory, emotion, social, eating, treatment burden, vitality, health perceptions, role, and weight. ${ }^{22}$ Each domain score ranges from 0 to 100 , and a cut-off of 50 points indicates good quality of life. CFQ was translated and validated for Brazilian Portuguese by Rozov et al. ${ }^{23}$

\section{Statistical Analysis}

Data was organized in an Excel spreadsheet and analyzed using the Statistical Package for Social

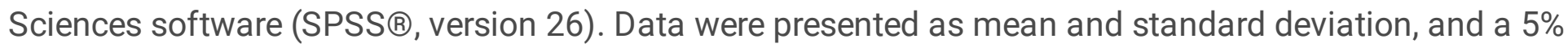
significance level was assigned for all analyses. We evaluated content validity, test-retest reliability, and convergent validity. Two types of reliability were assessed in total score and subscales of CF stigma scale: i) internal consistency, using Cronbach's alpha; and ii) test-retest reliability, calculated using Pearson's correlation between scores at baseline and after three weeks. Convergent validity was evaluated by comparing means of questionnaire scores using paired t-test.

\section{Results}

We were contacted by 60 individuals with $\mathrm{CF}$ after disclosure on social network. Fifty-seven individuals participated in the first phase of the study, and 52 answered the second phase. For psychometric evaluation, only data from individuals who completed both phases were used. Characteristics of participants are presented in Table 1. 
Table 1

Characteristics of study participants

\begin{tabular}{|ll|}
\hline Variable & Total \\
& N $=52(\%)$ \\
\hline Age (mean \pm standard deviation) & $26.8 \pm 7.3$ \\
\hline Sex & \\
\hline Female & $42(80.8)$ \\
\hline Male & $10(19.2)$ \\
\hline Ethnicity & \\
\hline Caucasian & $33(63.5)$ \\
\hline Other & $19(36.5)$ \\
\hline Education & \\
\hline Primary education & $10(19.3)$ \\
\hline Upper secondary education & $18(34.6)$ \\
\hline Post-graduation & $24(46.1)$ \\
\hline Live with & \\
\hline Parents & $29(55.4)$ \\
\hline Spouse/Partner & $21(40.4)$ \\
\hline Friends & $17(17.3)$ \\
\hline Alone & $32(61.5)$ \\
\hline Marital Status & $17(32.7)$ \\
\hline Single & $3(5.8)$ \\
\hline Married & $1(1.9)$ \\
\hline Divorced & \\
\hline Country Region & \\
\hline South & \\
\hline Southeast & \\
\hline Northeast & \\
\hline Northeast & \\
\hline Midwest & \\
\hline
\end{tabular}


Table 2 shows validity and reliability measurements. The Brazilian version of CF stigma scale showed adequate internal consistency $(a=0.836)$. Test-retest correlation $(n=52)$ was strong $(r=0.886, p<$ $0.0001)$. Paired t-test showed no significant difference between baseline and after three weeks $(19.4 \pm 4.7$ vs. $19.1 \pm 5.2, p=0.3$, respectively). The Brazilian version of CF stigma scale was positively correlated with GAD-7 scores $(r=0.384, p=0.005)$, but negatively correlated with SF12v2 $(r=-0.430, p=0.001)$ and CFQ $(r=-0.484, p<0.001)$ scores.

Table 2

Psychometric properties of the Brazilian version of CF stigma scale

\begin{tabular}{|c|c|c|c|}
\hline \multirow[t]{2}{*}{ Domains } & \multicolumn{3}{|c|}{ Correlations } \\
\hline & \multicolumn{3}{|l|}{$N=52$} \\
\hline \multicolumn{4}{|l|}{ Validity } \\
\hline SF-12v2 (r, p-value) & \multicolumn{3}{|c|}{$r=-0.430 p=0.001$} \\
\hline GAD-7 (r, p-value) & \multicolumn{3}{|c|}{$r=0.384 p=0.005$} \\
\hline CFQ (r, p-value) & \multicolumn{3}{|c|}{$r=-0.484 p<0.001$} \\
\hline \multicolumn{4}{|l|}{ Reliability } \\
\hline Internal consistency (a) & \multicolumn{3}{|l|}{0.836} \\
\hline Test-retest after three weeks & \multicolumn{3}{|c|}{$r=0.886 p<0.001$} \\
\hline \multicolumn{4}{|l|}{ (r, p-values) } \\
\hline \multirow[t]{2}{*}{$\begin{array}{l}\text { Mean difference between values of questionnaire items } \\
\text { (mean, SD) }\end{array}$} & Baseline & $\begin{array}{l}\text { After three } \\
\text { weeks }\end{array}$ & $\begin{array}{l}\mathrm{p}- \\
\text { value }\end{array}$ \\
\hline & $\begin{array}{l}19.4( \pm \\
4.7)\end{array}$ & $19.1( \pm 5.2)$ & $( \pm 0.3)$ \\
\hline $\begin{array}{l}\text { SF12v2: Short Form 12v2; GAD-7: General Anxiety Disor } \\
\text { Questionnaire; } p: p \text {-value; r: correlation coefficient; SD: } s\end{array}$ & $\begin{array}{l}\text { Q: Cystic F } \\
\text { 1 deviation }\end{array}$ & osis Quality & \\
\hline
\end{tabular}

Table 3 shows correlations between the score of Brazilian version of CF stigma scale and domains of SF12v2 and CFQ. We observed a negative correlation with mental domain of SF12v2 $(r=-0.382, p=$ $0.005)$ and the following domains of CFQ: physical $(r=-0.297, p=0.032)$, role $(r=-0.339, p=0.014)$, vitality $(r=-0.307, p=0.027)$, emotion $(r=-0.439, p=0.001)$, social $(r=-0.719, p<0.001)$, body image $(r=$ $-0.275, p=0.049)$, treatment burden $(r=-0.325, p=0.019)$, and health perceptions $(r=-0.522, p<0.001)$. 
Table 3

Correlations between CF stigma scale and domains of SF12v2 and CFQ.

\begin{tabular}{|ll|}
\hline Variables & CF Stigma \\
\hline Domains of SF12v2 & Correlation (r, p-value) \\
\hline Physical Score & $r=-0.149, p=0.292$ \\
\hline Mental Score** & $r=-0.382, p=0.005$ \\
\hline Domínios CFQ & \\
\hline Physical* & $r=-0.297, p=0.032$ \\
\hline Role* & $r=-0.339, p=0.014$ \\
\hline Vitality* & $r=-0.307, p=0.027$ \\
\hline Emotion** & $r=-0.439, p=0.001$ \\
\hline Social** & $r=-0.719, p<0.001$ \\
\hline Body Image* & $r=-0.275, p=0.049$ \\
\hline Eating & $r=0.036, p=0.800$ \\
\hline Treatment Burden* & $r=-0.325, p=0.019$ \\
\hline Health Perceptions** & $r=-0.522, p<0.001$ \\
\hline Weight & $r=0.059, p=0.679$ \\
\hline Respiratory* & $r=-0.304, p=0.029$ \\
\hline Digestive* & $r=-0.279, p=0,045$ \\
\hline $\begin{array}{l}\text { SF12v2: Short form of the SF-36v2 Health Survey, CFQ: Cystic Fibrosis Quality of Life Questionnaire, } \\
* 0<0.05, * * p<0.001 .\end{array}$ & \\
\hline
\end{tabular}

\section{Discussion}

Our study indicates that the Brazilian version of CF stigma scale is cross-culturally adapted and adequate for Brazilian individuals with CF. The Brazilian version showed substantial content validity, high internal consistency, convergent validity, and strong test-retest correlation. Results were similar to findings of Pakhale et al. ${ }^{11}$

The expert committee was composed of translators, individuals with $\mathrm{CF}$, and parents and/or guardians close to individuals with $\mathrm{CF}$, which contributed to robustness of translation and cross-cultural adaptation. Their presence might have favored semantic, conceptual, and contextual equivalence in all items. ${ }^{23-26}$ 
Psychometric properties show that the Brazilian version provides valid and reliable information about stigma in individuals with CF. The Brazilian version of CF stigma scale showed moderate negative correlations with mental domain of SF12v2 and emotion and health perceptions items of CFQ. It also showed a strong negative correlation with social item of CFQ. These results indicate that mental state, emotions, health, and social interactions influence the perception of stigma experience.

Despite the considerably high number of individuals included in this study, we were not able to attract individuals from different regions of the country or social, economic, and educational levels. Once the scale is validated for the Brazilian territory, it can be used by several professionals to confirm whether individuals with $\mathrm{CF}$ from various regions and specific contexts are experiencing stigma related to the disease. Furthermore, the Brazilian version of CF stigma scale can be associated with questionnaires assessing treatment adherence ${ }^{6}$ or outcomes that may trigger stigma.

The psychometric evaluation occurred during COVID-19 pandemic. Therefore, social isolation may have influenced the domains of quality of life and anxiety of questionnaires. However, we do not believe it affected the validation process because individuals were in social isolation in both phases of data collection. Another limitation of our study was that not all questionnaires used by Pakhale et al. ${ }^{11}$ were included in this study. For example, the Centre for Epidemiologic Studies Depression questionnaire was not used because it was not translated to Brazilian Portuguese. Last, data was collected with an interval of three weeks between phases, while Pakhale et al. ${ }^{11}$ used a three-month interval. Nevertheless, our results showed that this shorter interval did not influence the evaluation because no relevant changes were observed in scores.

\section{Conclusions}

CF stigma scale was translated and cross-culturally adapted to Brazilian Portuguese and exhibited favorable psychometric properties in Brazilian individuals with CF. Stigma caused by the disease affects patients and their families in different aspects of life, such as quality of life, emotions, socialization, and family relationships. Validating and cross-culturally adapting CF stigma scale is relevant for verifying its possible relationships with respiratory, psychosocial, and quality of life outcomes.

\section{Declarations}

\section{Ethics approval and consent to participate}

The study was submitted to the ethics committee of the Federal University of Rio Grande do Norte and received a favorable opinion (CAAE: 96606918.3.0000.5537). All participants signed an informed consent to participate and for publication, and the study was conducted in accordance with Declaration of Helsinki and Resolution 466/12 of the National Health Council - Brazil.

\section{Availability of data and materials}


All requests for raw and analyzed data and materials can be found at:

https://doi.org/10.5281/zenodo.6124881

All data are available from the authors upon reasonable request.

\section{Competing interests}

The authors declare that they have no competing interests.

\section{Author's contribution}

Oliveira, VH participated in the study's idealization, set up its methodological design, collected and analyzed the data and wrote the final version of the manuscript. Pakhale $S$, Balfour $L$ and Nogueira PAMS also participated in the study's idealization. Alchieri JC and Nogueira PAMS helped in the methodological design and in the data collection and interpretation of data. Mendonça KMPP, Nogueira IDB and Nogueira PAMS supervised the study. Silva WHBSS carried out a literature search and helped in the final version of the manuscript. Nogueira PAMS critically reviewed the manuscript. All authors read and approved the final manuscript.

\section{Funding}

The study did not receive financial support.

\section{Acknowledgments}

The authors thank Probatus Academic Services for providing scientific language translation, revision, and editing.

\section{References}

1. Dodge J, Lewis PA, Stanton M, Wilsher J. Cystic fibrosis mortality and survival in the UK: 1947-2003. Eur Respir J. 2007; 29(3):522-526, https://dx.doi.org/10.1183/09031936.00099506.

2. Oliver KN, Free ML, Bok C, McCoy KS, Lemanek KL, Emery CF. Stigma and optimism in adolescents and young adults with cystic fibrosis. J Cyst Fibros. 2014; 13(6):737-744, https://dx.doi.org/10.1016/j.jcf.2014.04.005.

3. Ferrin M, Cianci K, Finnerty M, McDonald G, Smith T, Thrasher S. Cystic Fibrosis in the workplace. The Questions, the Needs, The Solutions. Bethesda, MD: Cystic Fibrosis Foundation. 2003.

4. Lanzkron S, Sawicki GS, Hassell KL, Konstan MW, Liem RI, McColley SA. Transition to adulthood and adult health care for patients with sickle cell disease or cystic fibrosis: Current practices and research priorities. J Clin TransI Sci. 2018;2(5):334-342, https://dx.doi.org/10.1017/cts.2018.338.

5. Ernst MM, Johnson MC, Stark LJ. Developmental and Psychosocial Issues in Cystic Fibrosis. Child Adolesc Psychiatr Clin N Am. 2010;19(2):263-283, https://dx.doi.org/10.1016/j.chc.2010.01.004. 
6. Pizzignacco TMP, Mello DFD, Lima RAGD. Estigma e fibrose cística. Rev Lat Am Enfermagem. 2010; 18:139-142, https://doi.org/10.1590/S0104-11692010000100021.

7. Goffman E. Estigma: notas sobre a manipulação da identidade. Tradução: Mathias Lambert, 1988. 4.

8. Lebel S, Devins GM. Stigma in cancer patients whose behavior may have contributed to their disease. Future Oncol. 2008; 4(5): 717-73, https://doi.org/10.2217/14796694.4.5.717.

9. Berge JM, Patterson JM. Cystic fibrosis and the family: A review and critique of the literature. Families, Systems, \& Health. 2004; 22(1):74-100, https://doi.org/10.1037/1091-7527.22.1.74.

10. Pfeffer PE, Pfeffer JM, Hodson ME. The psychosocial and psychiatric side of cystic fibrosis in adolescents and adults. J Cyst Fibros. 2003; 2(2):61-68, https://dx.doi.org/10.1016/s15691993(03)00020-1.

11. Pakhale S, Armstrong M, Holly C, Edjoc, R, Gaudet E, Aaron S, Tasca G,Cameron W, Balfour L, et al. Assessment of stigma in patients with cystic fibrosis. BMC Pulm Med. 2014; 14(1): 76, https://dx.doi.org/10.1186/1471-2466-14-76.

12. Guillemin F, Bombardier C, Beaton D. Cross-cultural adaptation of health-related quality of life measures: literature review and proposed guidelines. J Clin Epidemiol. 1993; 46(12): 1417-1432, https://doi.org/10.1016/0895-4356(93)90142-n.

13. Beaton DE, Bombardier C, Guillemin F, Ferraz MB. Guidelines for the process of cross-cultural adaptation of self-report measures. Spine. 2000; 25(24):3186-91, https://doi.org/10.1097/00007632-200012150-00014.

14. Mokkink LB, Terwee CB, Patrick DL, Alonso J, Stratford PW, Knol DL, et al. The COSMIN study reached international consensus on taxonomy, terminology, and definitions of measurement properties for health-related patient-reported outcomes. J Clin Epidemiol. 2010; 63(7):737-745, https://dx.doi.org/10.1016/j.jclinepi.2010.02.006.

15. Marques JBV, Freitas DD. Método DELPHI: caracterização e potencialidades na pesquisa em Educação. Pro-Posições. 2018; 29(2):389-415, https://dx.doi.org/10.1590/1980-6248-2015-0140.

16. Pinheiro JQ, Farias TM, Abe-Lima JY. Painel de especialistas e estratégia multimétodos: reflexões, exemplos, perspectivas. Psico. 2013; 44(2): 184-92.

17. Powell C. The Delphi technique: myths and realities. J Adv Nurs. 2003; 41(4): 376-382, https://doi.org/10.1046/j.1365-2648.2003.02537.x.

18. Landis JR, Koch GG. The measurement of observer agreement for categorical data. Biometrics. 1977: 159-174, https://doi.org/10.2307/2529310.

19. Reichenheim ME, Moraes CL. Operacionalização de adaptação transcultural de instrumentos de aferição usados em epidemiologia. Rev Saude Publica. 2007; 41(4): 665-673, https://dx.doi.org/10.1590/s0034-89102006005000035.

20. Hair JF, Black WC, Babin BJ, Anderson RE, Thalam RL. Análise multivariada de dados. 5th ed. Porto Alegre: Bookman; 2005. p. 593. 
21. Moreno AL, DeSousa DA, Souza AMFLP, Manfro GG, Salum GA, Koller SH, Osório FL, Crippa JÁ, et al. Factor structure, reliability, and item parameters of the Brazilian-Portuguese version of the GAD-7 questionnaire. Temas em Psicologia. 2016; 24(1): 367-376, https://doi.org/10.1046/j.13652648.2003.02537.xdoi.org/10.9788/TP2016.1-25.

22. Quittner AL, Buu A, Messer MA, Modi AC, Watrous M. Development and validation of The Cystic Fibrosis Questionnaire in the United States: a health-related quality-of-life measure for cystic fibrosis. Chest. 2005; 128(4):2347-2354, https://doi.org/10.1378/chest.128.4.2347.

23. Rozov T, Cunha MT, Nascimento O, Quittner AL, Jardim JR. Linguistic validation of cystic fibrosis quality of life questionnaires. J Pediatr. 2006; 82(2):151-156, https://dx.doi.org/10.2223/jped.1463.

24. Ramada-Rodilla JM, Serra-Pujadas C, Delclós-Clanchet GL. Adaptación cultural y validación de cuestionarios de salud: revisión y recomendaciones metodológicas. Salud Publica Mex. 2013; 55(1): 57-66, https://dx.doi.org/10.1590/s0036-36342013000100009.

25. Sousa VD, Rojjanasrirat W. Translation, adaptation and validation of instruments or scales for use in cross-cultural health care research: a clear and user-friendly guideline. J Eval Clin Pract. 2011; 17(2): https://doi.org/10.1111/j.1365-2753.2010.01434.x.

26. Victal ML, Lopes MHBDM, D'Ancona CAL. Adaptação à cultura brasileira dos questionários The O'Leary-Sant e PUF, usados para cistite intersticial. Rev Esc Enferm USP. 2013; 47(2): 312-319, https://dx.doi.org/10.1590/s0080-62342013000200006.

\section{Supplementary Files}

This is a list of supplementary files associated with this preprint. Click to download.

- SupplementaryStatements.docx 